\title{
Accuracy and clinical performance of a continuous intra-arterial blood-gas monitoring system during thoracoscopic surgerył
}

\author{
A. Zollinger, D. R. Spahn, T. Singer, M. P. Zalunardo, S. Stoehr, W. Weder and \\ T. PASCH
}

\begin{abstract}
Summary
Accuracy and performance of the only currently available intra-arterial blood-gas monitoring system (Paratrend 7, PT7) were assessed in 23 patients during thoracoscopic surgery using onelung ventilation. Over a wide range of values for arterial $\mathrm{PO}_{2}(6.1-61.1 \mathrm{kPa}), \mathrm{PCO}_{2}(4.1-9.5 \mathrm{kPa})$ and $\mathrm{pH}$ (7.19-7.50), 138 arterial blood-gas values obtained by PT7 were compared with corresponding in vitro laboratory blood-gas measurements. We found good clinical performance with the PT7 and good agreement between PT7 values and in vitro measurements for arterial $\mathrm{PO}_{2}$ (bias (1.96 $\mathrm{SD})=0.38(9.52) \mathrm{kPa}), \mathrm{PCO}_{2}(0.31(0.76) \mathrm{kPa})$ and $\mathrm{pH}$ $(-0.017(0.065))$. Also, the bias for sequential changes between two consecutive times was not significantly different from the ideal value of 0 . We conclude that the PT7 is helpful in monitoring patients during thoracoscopy. (Br. J. Anaesth. 1997; 79: 47-52).
\end{abstract}

\section{Key words}

Measurement techniques, gass exchange. Equipment, bloodgas monitors. Surgery, thoracic. Ventilation, one-lung.

Video-assisted thoracoscopic surgery is used widely for an increasing number of diagnostic and therapeutic procedures in patients with compromised lung function. Additionally, one-lung ventilation (OLV) is necessary to provide a collapsed lung on the side of operation, and this is often associated with significant changes in arterial blood-gas tensions. Oxygenation may be impaired by significant intrapulmonary shunting, and carbon dioxide removal may be impaired by increased deadspace ventilation. Furthermore, lateral positioning of patients is usually necessary for an optimal surgical approach and may contribute further to ventilationperfusion mismatch resulting in compromised gas exchange. In order to prevent hypoxaemia and hypercapnia, repeated in vitro (laboratory) blood-gas analyses are performed frequently during OLV to control and adjust ventilation and oxygenation of the lungs. Continuous intra-arterial blood-gas monitoring would be advantageous because changes in oxygenation and carbon dioxide elimination can be recognized and treated immediately. ${ }^{1}$
The Paratrend 7 (Biomedical Sensors Ltd, Pfizer Hospital Products Group, High Wycombe, UK) is a fast-response intra-arterial blood-gas monitoring system which may be suitable for detection of rapid changes in arterial $\mathrm{PO}_{\mathrm{z}}, \mathrm{PCO}_{2}$ and $\mathrm{pH}$ values during thoracic surgery with OLV. It is currently the only commercially available intravascular blood-gas sensor system. The Paratrend 7 system (PT7), however, has been validated by only one group of authors in an experimental animal study ${ }^{2}$ and, for limited $\mathrm{PO}_{2}, \mathrm{PCO}_{2}$ and $\mathrm{pH}$ ranges, in the intensive care unit and during cardiac surgery. ${ }^{3-5}$

This study was performed to evaluate prospectively the clinical accuracy and performance of the Paratrend 7 intra-arterial blood-gas monitoring system during thoracoscopy over a wide range of $\mathrm{PO}_{2}, \mathrm{PCO}_{2}$ and $\mathrm{pH}$ values.

\section{Patients and methods}

Twenty-three patients undergoing elective thoracoscopic surgery gave their written informed consent to participate in this study, which was approved by the local Ethics Committee.

\section{INTRAVASCULAR BLOOD-GAS SENSOR}

The Paratrend 7 (PT7) is a multi-parameter sensor system incorporating four different sensors: $\mathrm{PO}_{2}$ is measured by a miniaturized Clark electrode, $\mathrm{PCO}_{2}$ and $\mathrm{pH}$ are measured by Optodes, and blood temperature is determined by a thermocouple. The four sensor elements are housed in a heparin-coated microporous polyethylene tubing of approximately $0.5 \mathrm{~mm}$ in diameter, suitable for insertion through a 20 -gauge or larger size catheter. The tip with the sensor elements, approximately $4 \mathrm{~cm}$ in length, has to float freely in the arterial lumen. The device with the blood-gas sensor incorporates a tubing system enabling simultaneous continuous intravascular arterial pressure measurement and intermittent

ANDREAS ZOLlinger, MD, DONAT R. SPAHN, MD, THOMAS Singer, mD, Marco P. Zalunardo, MD, Simone Stoehr, MD, Thomas Pasch, MD (Institute of Anaesthesiology); Walter WeDER, MD (Department of Surgery); University Hospital Zurich, CH-8091 Zurich, Switzerland. Accepted for publication: March 10, 1997.

+Presented in part at the annual meeting of the American Society of Anesthesiologists, Atlanta, October 21-25, 1995 
blood aspiration via a sideport for repeated in vitro laboratory blood-gas measurement. The disposable sensor is sealed by the manufacturer within a tonometer containing buffer solution, which maintains hydration and serves as a calibration medium. Before insertion into the patient, the sensor is calibrated under microprocessor control by the PT7 monitor using three precision gases bubbled through the tonometer. The calibration procedure takes 30 min. According to the manufacturer's guidelines, the sensor should be inserted into the artery within $8 \mathrm{~h}$ thereafter. Later, re-calibration of the system using the values of in vitro laboratory blood-gas determinations as a reference is only recommended every $12 \mathrm{~h}$. After insertion of the calibrated sensor, the PT7 monitor provides continuous graphical and numerical display of the measured values $\mathrm{PO}_{2}, \mathrm{PCO}_{2}$, and $\mathrm{pH}$. Temperature and calculated values $\mathrm{SO}_{2}$, $\mathrm{HCO}_{3-}$ and $\mathrm{BE}$ are displayed numerically.

Patients received oral premedication with midazolam $3.75-7.5 \mathrm{mg}, 30-45 \mathrm{~min}$ before transfer to the operating theatre. After insertion of an 18-gauge i.v. cannula (Adsyte, Becton Dickinson Vascular Access Inc., UT, USA), a radial artery (left/right $=16 / 7)$ was cannulated under local anaesthesia using a $5.1 \mathrm{~cm}$ long, 20-gauge catheter (Insyte, Becton Dickinson Vascular Access Inc., Sandy, UT, USA). A pressure transducer (Uniflow 43-600F, Baxter, Bentley Laboratories Europe, Uden, The Netherlands) was connected to the sideport of the previously calibrated PT7 sensor system for continuous intra-arterial pressure measurement. The pressure transducing tubes were prefilled with a solution of normal saline containing heparin $2 \mathrm{u}$. $\mathrm{ml}^{-1}$. While flushing continuously from a pressurized flush bag, the sensor was inserted through the radial cannula, advanced to a depth of $15 \mathrm{~cm}$ and attached to the skin with adhesive tape. Any movements of the hand were prevented to avoid kinking of the PT7 sensor. The arterial pressure waveform was displayed on a Hellige monitor (VICOM-SM SMU 612, PPG Hellige, Freiburg, Germany) and the continuous intra-arterial blood-gas measurements displayed on the PT7 monitor. Additional routine monitoring of patients consisted of five-lead ECG, pulse oximetry, rectal temperature measurement and measurements of end-tidal concentrations of carbon dioxide and inhalation anaesthetics (all VICOM-SM SMU 612, PPG Hellige, Freiburg, Germany). Anaesthesia was induced using thiopentone and fentanyl i.v. Neuromuscular block was produced with suxamethonium. Left endobronchial intubation was performed with a doublelumen tube (Sher-I-Bronch, Sheridan Catheter Corp., Argyle, NY, USA) under fibreoptic control. Enflurane in oxygen and air, fentanyl and pancuronium were used for maintenance of anaesthesia and neuromuscular block. Volume-controlled ventilation was used (Siemens Servo 900 D ventilator, Siemens Life Support Systems, Solna, Sweden), and ventilatory patterns were adjusted by an experienced anaesthetist tailored to the individual patient. Positioning of patients was performed according to surgical needs (left lateral 14 patients; right lateral eight patients; supine one patient). To provide a collapsed lung on the side of operation, OLV with an inspired oxygen fraction of 1.0 was induced on the contralateral side before skin incision for introduction of the trocar through the seventh or eighth intercostal space, and maintained throughout thoracoscopy. At the end of surgery a drainage tube was inserted and the collapsed lung was again ventilated.

\section{DATA COLLECTION}

The PT7 sensor was inserted immediately after the initial calibration procedure was completed in all cases, and was not re-calibrated thereafter. Data were obtained after induction of anaesthesia, 5, 10, and $20 \mathrm{~min}$ after the onset of OLV, before the end of OLV, and $10 \mathrm{~min}$ after two-lung ventilation was re-established. Provided that system stability was indicated by the PT7 computer according to the manufacturer's manual, arterial blood-gas values displayed on the PT7 monitor were stored at these times. Simultaneously, a $1-\mathrm{ml}$ blood sample was obtained for in vitro blood-gas analysis from the radial artery cannula using a pre-heparinized syringe (QS 50, Radiometer Medicals, Copenhagen, Denmark). In vitro measurement was performed within the next $2 \mathrm{~min}$ (IL 1400 BGE-analyzer with IL 482 co-oximeter, Instrumentation Laboratory, Milano, Italy) by a laboratory technician who was unaware of the in vivo PT7 values. Both PT7 and blood-gas analysis values were determined at $37{ }^{\circ} \mathrm{C}$ and thus no temperature correction was performed. Rectal and PT7 temperature readings were also recorded.

\section{DATA ANALYSIS}

All results were analysed using StatView 4.1 software (Abacus Concepts, Inc., Berkeley, CA) on an Apple Macintosh computer. Data are presented as mean (SD). Bias (mean of the differences PT7-blood-gas analysis (BGA)) and precision (1.96 SD of these differences) were calculated ${ }^{6}$ for arterial $\mathrm{pH}, \mathrm{PO}_{2}, \mathrm{PCO}_{2}$, $\mathrm{SO}_{2}, \mathrm{HCO}_{3^{-}}, \mathrm{BE}$ and temperature. Simple linear regression analyses were performed for arterial $\mathrm{PO}_{2}$, $\mathrm{PCO}_{2}, \mathrm{SO}_{2}, \mathrm{HCO}_{3}-\mathrm{BE}$ and temperature, but not for $\mathrm{pH}$ because of its logarithmic scale. The $\mathrm{pH}$ values, instead, were converted to $\left[\mathrm{H}^{+}\right]$, and linear regression analysis and calculation of bias and precision were performed. Furthermore, sequential changes in arterial $\mathrm{PO}_{2}, \mathrm{PCO}_{2}, \mathrm{pH}$ and $\left[\mathrm{H}^{+}\right]$between two consecutive times (delta $\mathrm{PO}_{2}$, delta $\mathrm{PCO}_{2}$, delta $\mathrm{pH}$, delta $\left[\mathrm{H}^{+}\right]$) were calculated for PT7 and BGA. Bias and precision of these changes were calculated for delta $\mathrm{PO}_{2}$, delta $\mathrm{PCO}_{2}$, delta $\mathrm{pH}$ and delta $\left[\mathrm{H}^{+}\right]$, and linear regression analyses were performed for delta $\mathrm{PO}_{2}$, delta $\mathrm{PCO}_{2}$ and delta $\left[\mathrm{H}^{+}\right]$. One-sample Sign tests were used to compare biases with the hypothesized ideal value of $0 . P<0.05$ was considered statistically significant.

\section{Results}

All 23 patients were studied (mean age 55 (range 20-76) yr; male/female ratio 17/6; ASA grade I, two patients, grade II, 12 patients, grade III, eight 
Table 1 Arterial blood-gas values obtained by the Paratrend 7 monitor (PT7) and by simultaneous in vitro bloodgas analysis (BGA). Arterial $\mathrm{PO}_{2}, \mathrm{PCO}_{2}$ and $\mathrm{pH}$ were measured by both systems, $\mathrm{HCO}_{3}$ - and $\mathrm{BE}$ were calculated by both systems, $\mathrm{SO}_{2}$ was measured by the co-oximeter and calculated by the Paratrend 7. $n=138$

\begin{tabular}{|c|c|c|c|c|c|c|}
\hline & \multicolumn{2}{|l|}{ Mean (SD) } & \multicolumn{2}{|c|}{ Minimum } & \multicolumn{2}{|c|}{ Maximum } \\
\hline & PT7 & BGA & PT7 & BGA & PT7 & BGA \\
\hline $\mathrm{PO}_{2}(\mathrm{kPa})$ & $24.3(15.8)$ & $24.0(14.5)$ & 5.7 & 6.1 & 72.9 & 61.1 \\
\hline $\mathrm{PCO}_{2}(\mathrm{kPa})$ & $6.0(0.8)$ & $5.7(0.9)$ & 4.5 & 4.1 & 9.9 & 9.5 \\
\hline $\mathrm{pH}$ & $7.37(0.06)$ & $7.39(0.05)$ & 7.19 & 7.19 & 7.47 & 7.50 \\
\hline $\mathrm{HCO}_{3}-\left(\mathrm{mmol}\right.$ litre $\left.^{-1}\right)$ & $25.9(2.1)$ & $25.6(1.4)$ & 21.4 & 21.3 & 33.5 & 28.8 \\
\hline $\mathrm{BE}\left(\mathrm{mmol}\right.$ litre $\left.^{-1}\right)$ & $0.6(2.7)$ & $1.0(1.5)$ & -6.2 & -4.5 & 8.6 & 3.7 \\
\hline $\mathrm{SO}_{2}(\%)$ & $97.0(4.1)$ & $95.3(4.9)$ & 78.7 & 73.8 & 99.9 & 99.7 \\
\hline
\end{tabular}

Table 2 Results of comparisons between Paratrend 7 readings and simultaneous in vitro blood-gas determinations. Arterial $\mathrm{PO}_{2}, \mathrm{PCO}_{2}$ and $\mathrm{pH}$ were measured by both systems, $\mathrm{HCO}_{3}$-and $\mathrm{BE}$ were calculated by both systems. So was measured by the co-oximeter and calculated by the Paratrend $7 .[\mathrm{H}+]$ was calculated from the $\mathrm{pH}$ values measured by both systems to allow linear regression analysis. $n=138$. ${ }^{\star} P<0.05, \star \star \star P<0.0001$, compared with hypothesized ideal value of 0 . Regression line equation $y=\mathrm{a}+b \times x: y=$ Paratrend 7 readings, $x=$ in vitro blood-gas determinations, $a=$ axis intercept, $b=$ regression coefficient (slope), $r=$ correlation coefficient

\begin{tabular}{|c|c|c|c|c|c|}
\hline & $a$ & $b$ & $r$ & Bias & Precision \\
\hline $\mathrm{PO}_{2}(\mathrm{kPa})$ & -0.64 & 1.04 & 0.95 & 0.38 & 9.52 \\
\hline $\mathrm{PCO}_{2}(\mathrm{kPa})$ & 1.04 & 0.87 & 0.90 & $0.31^{\star \star \star}$ & 0.76 \\
\hline $\mathrm{pH}$ & - & - & - & $-0.017^{\star \star \star}$ & 0.065 \\
\hline $\mathrm{HCO}_{3-}\left(\mathrm{mmol}\right.$ litre $\left.{ }^{-1}\right)$ & 9.73 & 0.63 & 0.43 & $0.3^{\star}$ & 3.9 \\
\hline $\mathrm{BE}\left(\mathrm{mmol}\right.$ litre $\left.^{-1}\right)$ & -0.36 & 1.00 & 0.56 & -0.4 & 4.4 \\
\hline $\mathrm{SO}_{2}(\%)$ & 25.4 & 0.7 & 0.82 & $1.7^{\star \star \star}$ & 5.5 \\
\hline$\left[\mathrm{H}^{+}\right]\left(\right.$nmol litre $\left.^{-1}\right)$ & 4.69 & 0.93 & 0.84 & $1.76^{\star \star \star}$ & 6.62 \\
\hline
\end{tabular}

Table 3 Temperature obtained by the Paratrend 7 sensor in the radial artery (Temp PT7, ${ }^{\circ} \mathrm{C}$ ) and by simultaneous rectal temperature measurement (Temp rect, ${ }^{\circ} \mathrm{C}$ ). $n=138 .{ }^{\star \star \star} P<0.0001$ compared with hypothesized ideal value of $0 . \operatorname{Min} / \operatorname{Max}=\operatorname{Minimum} / \mathrm{maximum}$ values. Regression line equation $y=a+b \times x: y=$ Paratrend 7 radial temperature measurement, $x=$ rectal temperature measurement, $a=$ axis intercept, $b=$ regression coefficient (slope), $r=$ correlation coefficient

\begin{tabular}{|c|c|c|c|c|c|c|c|}
\hline & Mean (SD) & Min/Max & $a$ & $b$ & $r$ & Bias & Precision \\
\hline Temp PT7 & $35.9^{`}(0.9)$ & $32.0 / 37.2$ & & & & & \\
\hline Temp rect & $36.1(0.6)$ & $34.5 / 37.5$ & 9.55 & 0.72 & 0.48 & $-0.5^{\star \star \star}$ & 1.6 \\
\hline
\end{tabular}

Table 4 Sequential changes in arterial blood-gas tensions between two consecutive times $\left(\mathrm{delta}_{\mathrm{PO}_{2}}\right.$, delta $P \mathrm{CO}_{2}$, delta $\mathrm{pH})$ : results of comparisons between Paratrend 7 readings and simultaneous in vitro blood-gas determinations. Delta $[\mathrm{H}+]$ was calculated from the $\mathrm{pH}$ values measured by both systems to allow linear regression analysis. $n=115$. No significant differences from the hypothesized ideal value of 0 . Regression line equation $y=a+b \times x: y=$ Paratrend 7 readings, $x=$ in vitro blood-gas determinations, $a=$ axis intercept, $b=$ regression coefficient (slope), $r=$ correlation coefficient

\begin{tabular}{lccccc}
\hline & $a$ & $b$ & $r$ & Bias & Precision \\
\hline Delta $\mathrm{PO}_{2}(\mathrm{kPa})$ & 0.27 & 1.03 & 0.97 & 0.28 & 9.04 \\
Delta $\mathrm{PCO}_{2}(\mathrm{kPa})$ & -0.01 & 0.87 & 0.87 & 0.01 & 0.59 \\
Delta $\mathrm{pH}$ & - & - & - & 0.001 & 0.035 \\
Delta $\left[\mathrm{H}^{+}\right](\mathrm{nmol} \mathrm{litre}$ & $-1)$ & 0.06 & 0.93 & 0.87 & 0.08 \\
\hline
\end{tabular}

patients, grade IV, one patient). The operations performed were: lung resection (14), pleurectomy (six), bullectomy (two) and sympathectomy (one). Duration of anaesthesia was 220 (68) min, duration of operation was 106 (61) min and duration of OLV was 99 (58) min. All PT7 sensors calibrated and inserted into a radial artery measured intra-arterial blood-gas tensions throughout the study and there were no technical failures. According to the study design, six measurements in 23 patients were performed, producing 138 PT7 readings with corresponding blood-gas analysis values. Positioning of patients and diathermy did not affect sensor function. No complications attributable to the sensor were observed.

On average, near normal arterial $\mathrm{PCO}_{2}$ and high $\mathrm{PO}_{2}$ values were found (table 1 ). However, extreme blood-gas values were observed during thoracoscopic surgery and OLV, which offered the opportunity to study the accuracy of the PT7 over a wide range of blood-gas analysis values (table 1 ). $\mathrm{PT} 7-\mathrm{PO}_{2}$ corresponded very well with $\mathrm{BGA}-\mathrm{PO}_{2}$, as evidenced by non-significant bias $(0.38 \mathrm{kPa})$ and a correlation coefficient of 0.95 (table 2, fig. 1). Also, PT7- $\mathrm{PCO}_{2}$ corresponded well with $\mathrm{BGA}-\mathrm{PCO}_{2}$, as documented by a bias of $0.31 \mathrm{kPa}(P<0.0001)$ and a correlation 

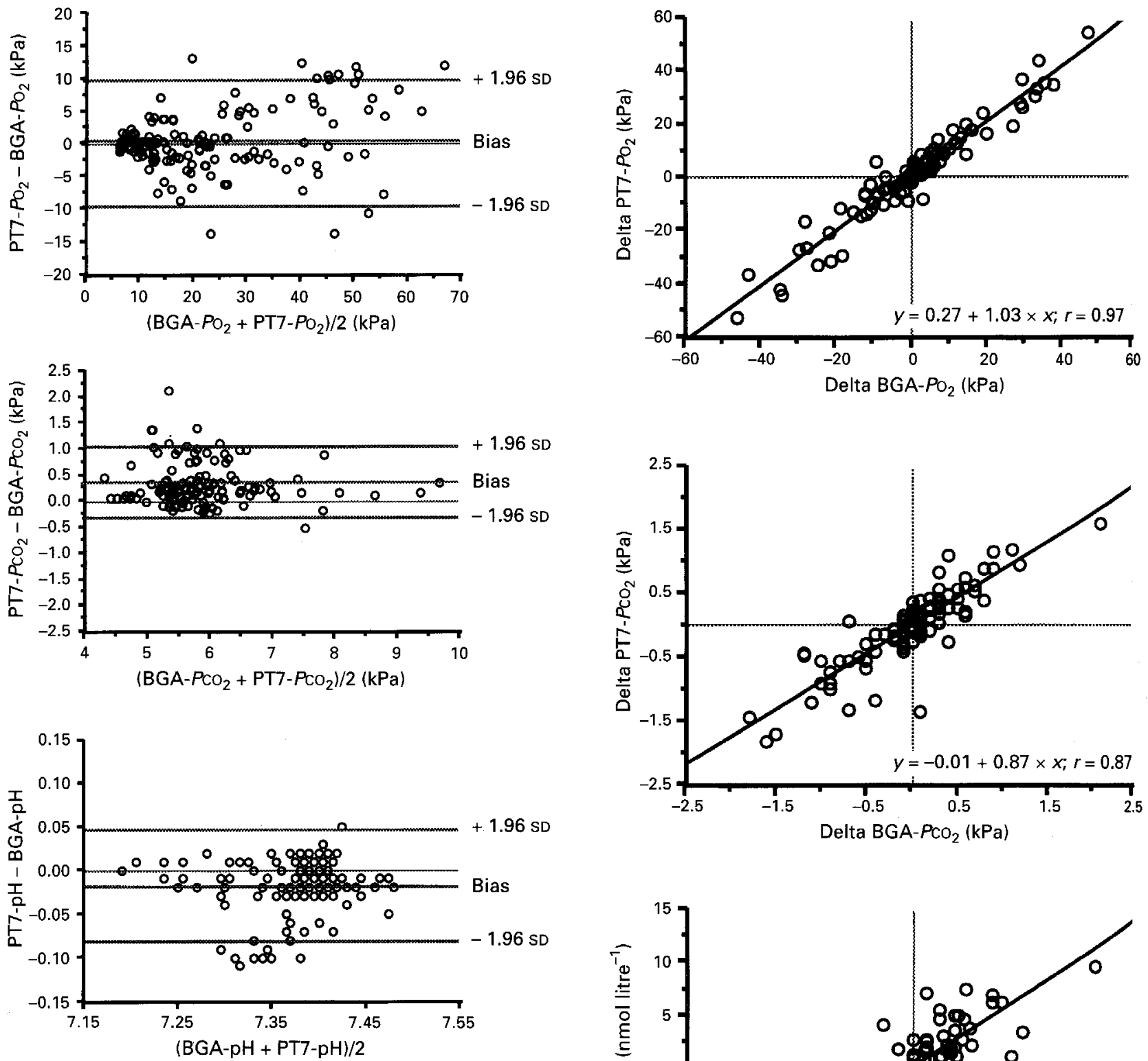

Figure 1 Bland Altman plots ${ }^{6}$ showing bias (mean of differences) and precision (1.96 SD of these differences) vs mean values of arterial $\mathrm{PO}_{2}, \mathrm{PCO}_{2}$ and $\mathrm{pH}$ obtained by Paratrend 7 (PT7) compared with values obtained by in vitro blood-gas measurement using a co-oximeter (BGA). $n=138$.

coefficient of 0.90 (table 2, fig. 1). Furthermore, the calculated $\left[\mathrm{H}^{+}\right]$concentrations derived from the PT7-pH values correlated well with those derived from BGA-pH (correlation coefficient 0.84) (table 2). Bias between PT7-pH and BGA-pH was relatively small $(-0.017 ; P<0.0001)$ (table 2 , fig. 1 ). However, agreement of the calculated values $\mathrm{HCO}_{3}$ (0.43) and BE (0.56) was relatively poor (table 2). Mean PT7 radial temperature values were lower than those recorded rectally (table 3 ). The bias of the sequential changes between two consecutive times (delta $\mathrm{PO}_{2}$, delta $\mathrm{PCO}_{2}$, delta $\mathrm{pH}$, delta $\left[\mathrm{H}^{+}\right]$) was not significantly different from the hypothesized ideal value of 0 (table 4), and a good correlation coefficient between BGA and PT7 was found for the values delta $\mathrm{PO}_{2}(0.97)$, delta $\mathrm{PCO}_{2}(0.87)$ and delta $\left[\mathrm{H}^{+}\right]$(0.87) (table 4, fig. 2).
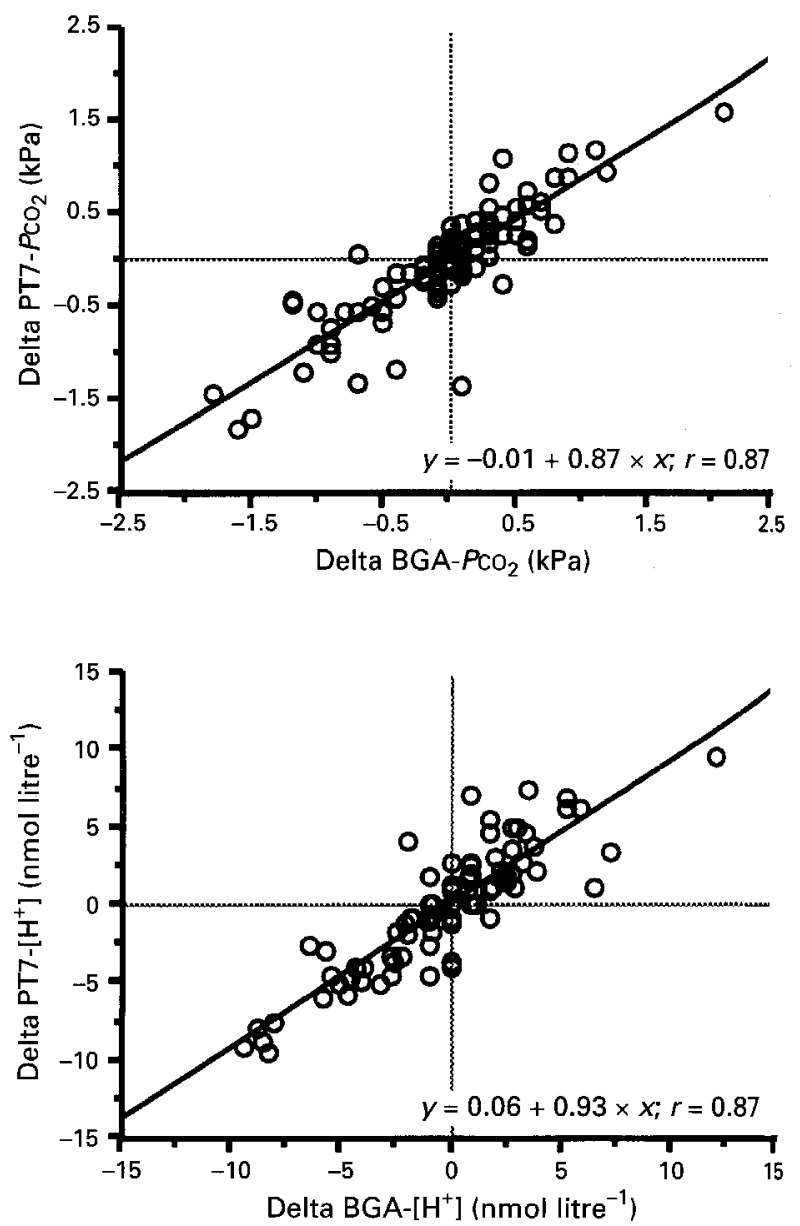

Figure 2 Linear regression analysis plots showing sequential changes in arterial $\mathrm{PO}_{2}, \mathrm{PCO}_{2}$ and $\left[\mathrm{H}^{+}\right]$between two consecutive times (delta $\mathrm{PO}_{2}$, delta $\mathrm{PCO}_{2}$, delta $\left[\mathrm{H}^{+}\right]$) obtained by Paratrend 7 (PT7) vs corresponding changes obtained by in vitro blood-gas measurement using a co-oximeter (BGA). $n=115$.

\section{Discussion}

The results of this study indicate good clinical performance of the Paratrend 7 multi-parameter sensor. In all patients the sensor was inserted into the radial artery catheter without difficulties and accurately measured arterial blood-gas tensions continuously during thoracoscopy over a wide range of $\mathrm{PO}_{2}, \mathrm{PCO}_{2}$ and $\mathrm{pH}$ values (see tables 1 and 2; fig. 1). 
The correlation of $\mathrm{So}_{2}$ values calculated by the PT7 compared with in vitro values determined by the co-oximeter was also satisfactory (table 2). However, radial PT7 temperature compared with rectal temperature (table 3), and values of $\mathrm{HCO}_{3}-$ and $\mathrm{BE}$ calculated by and displayed on the Paratrend 7 monitor showed poor correlation with those calculated from the in vitro blood-gas determinations (table 2).

Thoracoscopy necessitates OLV with close monitoring of arterial blood-gas tensions. Intermittent blood-gas measurement is currently standard care and insertion of an intra-arterial catheter is usually required. Although this represents a "continuously invasive" method, blood-gas determination is still only intermittent. Recently, serious shortcomings of conventional intermittent blood-gas analyses have been discussed. ${ }^{7-10}$ The most obvious disadvantage is the dependence on clinical judgement as to when blood samples should be obtained. Adequate and immediate detection of serious events by the anaesthetist is presumed, blood has to be sampled in time and the results should be available rapidly. In many critical situations, however, blood sampling, transport and laboratory analysis is only possible with a considerable delay, and sampling rate is inherently limited. Thus intermittent blood-gas measurement represents a "snapshot" of a continuous physiological variable and is frequently obtained after a critical event has already occurred. ${ }^{7}$ Continuous intraarterial blood-gas monitoring, on the other hand, provides relevant physiological information on-line, including display of trends of measured variables. Furthermore, alarm limits for the variables may be defined. Continuous intra-arterial blood-gas monitoring is therefore desirable, provided that such a system is accurate.

Several clinical studies on the performance of intravascular sensor systems have been published ${ }^{3-59-16}$ and the results have been reviewed recently. ${ }^{1718}$ None of these systems, however, is available commercially, except for the PT7. Unfortunately, the PT7 system has been validated clinically by only one team of investigators in collaboration with the manufacturer. ${ }^{3-5}$ Assessing accuracy and clinical performance of the PT7 system independently is therefore important. In thoracoscopy, using OLV, we had the opportunity to assess the accuracy of the PT7 system over a wide range of arterial $\mathrm{PO}_{2}$ $(6.1-61.1 \mathrm{kPa}), \quad \mathrm{PCO}_{2} \quad(4.1-9.5 \mathrm{kPa})$ and $\mathrm{pH}$ (7.19-7.50) values. We found good agreement of PT7 values and in vitro blood-gas analysis values for arterial $\mathrm{PO}_{2}, \mathrm{PCO}_{2}$ and $\mathrm{pH}$ (fig. 1, table 2). This is in keeping with previous studies in intensive care medicine $^{3}$ and cardiac surgery. ${ }^{45}$ Furthermore, comparison of sequential changes between two consecutive times (delta $\mathrm{PO}_{2}$, delta $\mathrm{PCO}_{2}$, delta $\mathrm{pH}$ ) showed good agreement (table 4, fig. 2), and no clinically relevant changes in PT7 values compared with changes in blood-gas analysis values were observed. This is of the utmost importance for a continuous monitoring system, as it is designed primarily to accurately reflect trends in measured variables.

Radial PT7 temperature was significantly lower than rectal temperature (table 3). This is not surprising as the radial artery may be considered an intermediate or even a peripheral temperature measuring site: core temperature is reflected more accurately by rectal rather than axillary temperature measurements during anaesthesia. ${ }^{19}$ Therefore, both PT7 and blood-gas analysis values were determined at $37^{\circ} \mathrm{C}$ in this methodological study. The PT7 system, however, offers the choice between measurement of blood-gas tensions at $37^{\circ} \mathrm{C}$ (as performed in this investigation) and at patient (intravascular) temperature. Comparison of the two methods was not the object of this study.

Comparing PT7 and laboratory blood-gas analysis results is difficult because laboratory blood-gas analysis measurement is fraught with a variety of problems: samples for blood-gas analysis may easily be handled incorrectly by sample dilution, excess heparinized saline, ${ }^{2021}$ delays in analysis with the sample being stored at room temperature, ${ }^{2022}$ oxygen consumption from metabolism by leucocytes and other cells contained in the sample, ${ }^{23}$ diffusion of gases through the plastic wall of syringes ${ }^{24-26}$ and pressure of air bubbles in the samples, ${ }^{222627}$ particularly during transport. ${ }^{28}$ In addition, the accuracy and variability of laboratory blood-gas analysers are applied in a recent evaluation of blood-gas analysers ${ }^{29}$ : in the $\mathrm{PO}_{2}$ range of $4-20 \mathrm{kPa}$ and $\mathrm{PCO}_{2}$ range of $2.7-10.6 \mathrm{kPa}$, respectively, $95 \%$ of measurements should be within $\pm 7.5 \%$ or $\pm 0.6 \mathrm{kPa}$ of a reference; for $\mathrm{PO}_{2}>20 \mathrm{kPa}$ and $\mathrm{PCO}_{2}>10.6 \mathrm{kPa}$, respectively, $95 \%$ of measurements should be within $\pm 12.5 \%$ of a reference; $\mathrm{pH}$ accuracy cannot be tested because there is no reference method. ${ }^{29}$ Differences between PT7 and laboratory blood-gas values thus cannot $a$ priori be considered to represent variability in the new method, that is the PT7, but may also result from errors in laboratory blood-gas analysis or in both of these methods.

The observed variability of $\mathrm{PT} 7 \mathrm{PO}_{2}, \mathrm{PCO}_{2}$ and $\mathrm{pH}$ measurements is acceptable for clinical decision making, and PT7 is a reliable trend indicator of arterial blood-gas tensions. During thoracoscopy with OLV, in selected cases, continuous intraarterial blood-gas monitoring is therefore helpful in monitoring oxygenation and carbon dioxide. However, cost effectiveness and influence on outcome of this particular technology must be examined. ${ }^{3031}$ Whether the good clinical performance will translate into improved long-term outcome has not yet been investigated and requires further study. ${ }^{32-34}$

In summary, we found good accuracy and good clinical performance of the Paratrend 7 sensor system when used in patients during thoracoscopy. It appears to be a helpful tool in monitoring patients during surgical procedures associated with large variations in arterial blood-gas tensions, such as thoracoscopy with OLV.

\section{Acknowledgements}

We thank Claudia Stoll, Anne-Barbara Kroeber and Leo Beck, nurse anaesthetists, and Dragoljub Popovic and Thoaimieu Baer, laboratory technicians. 


\section{References}

1. Greenblott GB, Tremper KK, Barker SJ, Gerschultz S, Gehrich JL. Continuous blood gas monitoring with an intraarterial optode during one-lung anesthesia. Fournal of Cardiothoracic and Vascular Anesthesia 1991; 5: 365-367.

2. Clutton-Brock TH, Fink S, Markle D, Luthra AJ, Hendry SP. The evaluation of a new intravascular blood gas monitoring system in the pig. Fournal of Clinical Monitoring 1994; 10: 387-391.

3. Venkatesh B, Clutton-Brock TH, Hendry SP. A multiparameter sensor for continuous intra-arterial blood gas monitoring: a prospective evaluation. Critical Care Medicine 1994; 22: 588-594.

4. Venkatesh B, Clutton-Brock TH, Hendry SP. Evaluation of the Paratrend 7 intravascular blood gas monitor during cardiac surgery: comparison with the C4000 in-line blood gas monitor during cardiopulmonary bypass. Fournal of Cardiothoracic and Vascular Anesthesia 1995; 9: 412-419.

5. Venkatesh B, Clutton-Brock TH, Hendry SP. Continuous measurement of blood gases using a combined electrochemical and spectrophotometric sensor. Fournal of Medical Engineering and Technology 1994; 18: 165-168.

6. Bland JM, Altman DG. Statistical methods for assessing agreement between two methods of clinical measurement. Lancet 1986; 1: 307-310.

7. Mahutte CK. Continuous intra-arterial blood gas monitoring. Intensive Care Medicine 1994; 20: 85-86.

8. Shapiro BA. In vivo monitoring of arterial blood gases and pH. Respiratory Care 1992; 37: 165-169.

9. Larson CP, Vender J, Seiver A. Multisite evaluation of a continuous intraarterial blood gas monitoring system. Anesthesiology 1994; 81: 543-552.

10. Roupie EE, Brochard L, Lemaire FJ. Clinical evaluation of a continuous intra-arterial blood gas system in critically ill patients. Intensive Care Medicine 1996; 22: 1162-1168.

11. Barker SJ, Hyatt J. Continuous measurement of intraarterial pHa, $\mathrm{PaCO}_{2}$, and $\mathrm{PaO}_{2}$ in the operating room. Anesthesia and Analgesia 1991; 73: 43-48.

12. Smith BE, King PH, Schlain L. Clinical evaluationcontinuous real-time intra-arterial blood gas monitoring during anesthesia and surgery by fiber optic sensor. International fournal of Clinical Monitoring and Computing 1992; 9: 45-52.

13. Zimmerman J, Dellinger R. Initial evaluation of a new intraarterial blood gas system in humans. Critical Care Medicine 1993; 21: 495-500.

14. Haller M, Kilger E, Briegel J, Polasek J, Horst H, Groh J, Peter K. Continuous intravascular blood gas analysis (in German). Anaesthesist 1994; 43: 642-647.

15. Haller M, Kilger E, Briegel J, Forst H, Peter K. Continuous intra-arterial blood gas and $\mathrm{pH}$ monitoring in critically il patients with severe respiratory failure: a prospective criterion standard study. Critical Care Medicine 1994; 22: 580-587.

16. Kurahashi K, Hirose Y, Yamada H, Toyoshima M, Usuda Y. Intra-arterial blood gas monitoring system: more accurate values can be obtained. Fournal of Clinical Monitoring 1996; 12: $141-147$.
17. Shapiro BA. Blood gas monitors in the critical care setting. Current Opinion in Critical Care 1995; 1: 191-196.

18. Venkatesh B, Hendry SP. Continuous intra-arterial blood gas monitoring. Intensive Care Medicine 1996; 22: 818-828.

19. Cork RC, Vaughan RW, Humphrey LS. Precision and accuracy of intraoperative temperature monitoring. Anesthesia and Analgesia 1983; 62: 211-214.

20. Hamilton RD, Crockett AJ, Alpers JH. Arterial blood gas analysis: potential errors due to the addition of heparin. Anaesthesia and Intensive Care 1978; 6: 251-255.

21. Dennis RC, Ng R, Yeston NS, Statland B. Effect of sample dilutions on arterial blood gas determination. Critical Care Medicine 1985; 13: 1067-1068.

22. Biswas CK, Ramos JM, Agroyannis B, Kerr DNS. Blood gas analysis: Effect of air bubbles in syringe and delay in estimation. British Medical fournal 1982; 284: 923-927.

23. Hess CE, Nichols AB, Hunt WB, Suratt PM Pseudohypoxemia secondary to leukemia and thrombocytosis. New England fournal of Medicine 1979; 301: 361-363.

24. Scott PV, Horton JN, Mapleson WW. Leakage of oxygen from blood and water samples stored in plastic and glass syringes. British Medical fournal 1971; 3: 512-516.

25. Evers W, Racz GB, Levy AA. A comparative study of plastic (polypropylene) and glass syringes in blood-gas analysis. Anesthesia and Analgesia 1972; 51: 92-97.

26. Harsten A, Berg B, Inerot S, Muth L. Importance of correct handling of samples for the results of blood gas analysis. Acta Anaesthesiologica Scandinavica 1988; 32: 365-368.

27. Mueller RG, Lang GE, Beam JM. Bubbles in samples for blood gas determinations. A potential source of error. American fournal of Clinical Pathology 1976; 65: 242-249.

28. McKane MH, Southorn PA, Santrach PJ, Burritt MF, Plevak DJ. Sending blood gas specimens through pressurized transport tube systems exaggerates the error in oxygen tension measurements created by the presence of air bubbles. Anesthesia and Analgesia 1995; 81: 179-182.

29. ECRI (Emergency Care Research Institute). Evaluation blood gas/pH analyzers. Health Devices 1995; 24: 208-243.

30. Franklin C. Basic concepts and fundamental issues in technology assessment. Intensive Care Medicine 1993; 19. 117-121.

31. Byrick RJ, Cohen MM. Technology assessment of anaesthesia monitors: problems and future directions. Canadian Fournal of Anaesthesia 1995; 42: 234-239.

32. Blitt CD. Is continuous intra-arterial blood gas and $\mathrm{pH}$ monitoring justifiable? fournal of Clinical Monitoring 1996; 12 177.

33. Gilbert HC, Vender JS. Pro: Is continuous intra-arterial blood gas and $\mathrm{pH}$ monitoring justifiable? fournal of Clinical Monitoring 1996; 12: 179-181.

34. Hoffer JL, Norfleet EA. Con: Is continuous intra-arterial blood gas and $\mathrm{pH}$ monitoring justifiable? Fournal of Clinical Monitoring 1996; 12: 183-189. 